\title{
Block Copolymer Vesicles in Liquid $\mathrm{CO}_{2}$
}

William F. Edmonds, Marc A. Hillmyer, and Timothy P. Lodge

\section{SUPPORTING INFORMATION}

The LF block copolymers were characterized by ${ }^{1} \mathrm{H}$ and ${ }^{19} \mathrm{~F}$ nuclear magnetic resonance spectroscopy. Upon reaction with the acid-chloride-end-functionalized PFPO homopolymer, the methine proton peak, c', shifted downfield and was no longer resolved due to the presence of the peak for the methine protons of the repeat unit, c. Reacting the hydroxy-terminated polylactide with trifluoroacetic anhydride (TFAA) results in a peak shift that is consistent with that of the coupling reaction.

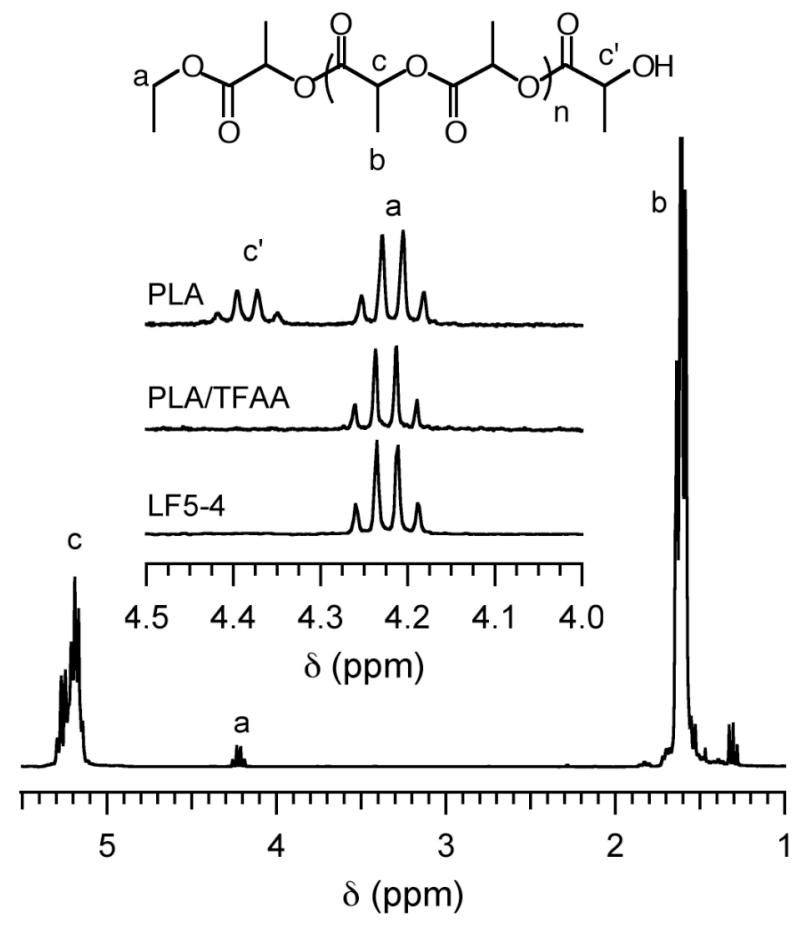

Figure S1. ${ }^{1} \mathrm{H}$ NMR spectra for the PLA homopolymer, the polymeric precursor reacted with trifluoroacetic anhydride, and the block copolymer LF5-4.

The copolymer was further characterized by size exclusion chromatography. The trace for the block copolymer exhibited a shift to lower elution volume, which is consistent with the increase in 
molecular weight. Note the mobile phase was tetrahydrofuran, a selective solvent for PLA, therefore the broad shoulder at an elution volume of $20 \mathrm{~mL}$ likely corresponds to micelles. In addition, the small, negative peak at an elution volume of $30 \mathrm{~mL}$ is most likely attributed to homopolymer PFPO impurity.

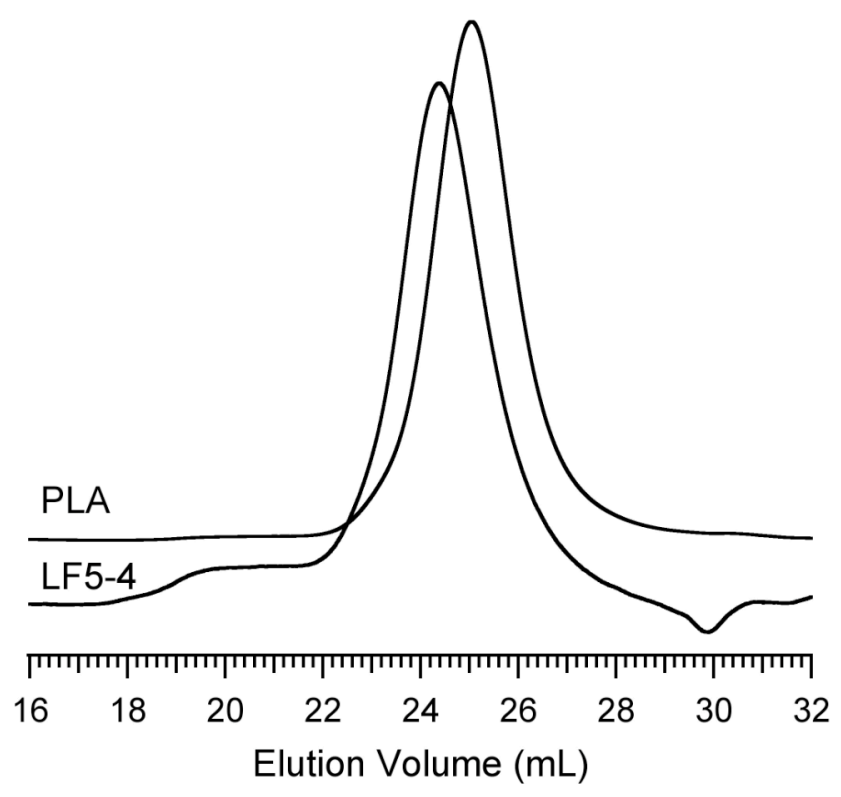

Figure S2. Size exclusion chromatographs for the PLA precursor and the LF5-4 diblock copolymer in a mobile phase of THF.

The cloud point measurements were performed using a home-built instrument, illustrated in Figure S3. The cylindrical cell was machined from 316 stainless steel. The cell had a diameter of 2.5 in and was 3.25 in long. The sample chamber had a depth of 1.25 in and a diameter of 1 in, resulting in a total cell volume of approximately $16 \mathrm{~mL}$. The view port was a single sapphire window (Crystal Systems); the window diameter was 1.625 in and 0.5 in thick. The view port high-pressure seal was formed using a Teflon o-ring and a stainless steel bushing; the design allows for viewing of the entire cell volume. The cell had four ports: one connected to a high-pressure pump (High Pressure Equipment, Model 81-5.75-10), another for direct temperature measurement, another for measuring the system pressure (Omegadyne, PX91NO-60KSV), and the fourth for venting the system. Note the sample volume includes the active chamber of the high-pressure, diaphragm pump; this setup facilitated precise 
control over the sample volume and, hence, the system pressure. The cell assembly was hydrostatically tested for pressures up to 550 bar and temperatures up to $100{ }^{\circ} \mathrm{C}$. The cell temperature was maintained using heating tape and a temperature controller (Omega, CN-7700).



Figure S3. Schematic illustration of the cloud point measurement device.

A schematic of the high-pressure dynamic light scattering setup is illustrated in Figure S4. The scattering cell was mounted on a stir plate. The inlet to the cell was controlled using a 3-way needle valve (High Pressure Equipment), providing continuous connection between the pressure transducer (Omegadyne) and the scattering cell volume. The temperature of the cell was controlled using cartridge heaters and a temperature controller (Omege, $\mathrm{CN}-7700)$. In contrast to the variable-volume cell, the thermocouple was embedded in the cell housing and was not in intimate contact with the solution. Control of the system temperature was important as subtle changes gave rise to density fluctuations of the scattering solution, which in turn complicated the measured scattered intensity fluctuations. The system inlet was connected to a 3-way ball valve (High Pressure Equipment), which was connected to the $\mathrm{CO}_{2}$ source and a vent assembly. $\mathrm{CO}_{2}$ was supplied to the cell using an ISCO high-pressure pump via the 3-way valve; the pump was rated up to $10 \mathrm{kpsi}$. In a typical scattering experiment, the cell was filled with $\mathrm{CO}_{2}$ and then isolated from the rest of the setup using the 3-way needle valve. 


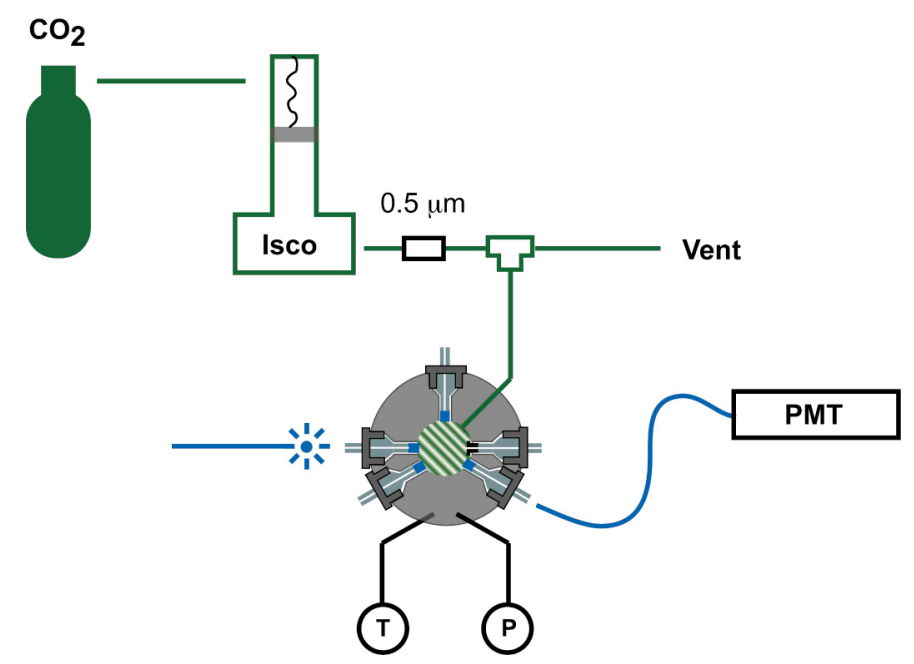

Figure S4. Schematic illustration of the high-pressure dynamic light scattering setup.

To ensure that no structural evolution of the LF5-4 micelles in $\mathrm{CO}_{2}$ occurred during the long time cooling from ambient temperature to $-1{ }^{\circ} \mathrm{C}$, we measured the $\mathrm{R}_{\mathrm{h}}$ of the micelles in situ at $5 \pm 2{ }^{\circ} \mathrm{C}$ and 400 bar. The solution was maintained at the final temperature for $24 \mathrm{~h}$. Figure S5 compares the distribution of particle sizes at both experimental temperatures and definitively indicates that there is no change associated with the cooling process.

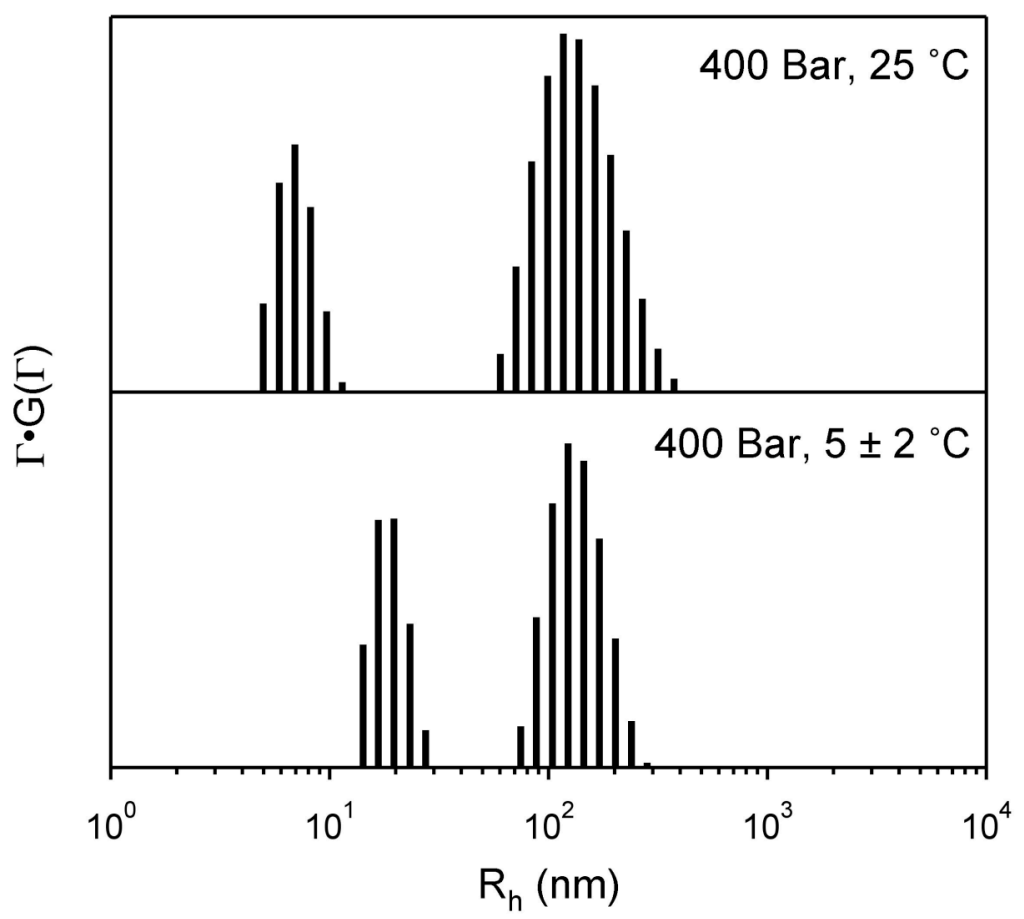

Figure S5. Distribution of $\mathrm{R}_{\mathrm{h}}$ values for a solution of LF5-4 in condensed $\mathrm{CO}_{2}$ at 25 and $5{ }^{\circ} \mathrm{C}$ and 400 bar; the inversion of the intensity correlation data was accomplished using CONTIN. 
Finally, the solution of quenched micelles was prepared in $\mathrm{CO}_{2}$ at 350 bar and ambient temperature, while the solution measured in situ was prepared at 400 bar. HP-DLS data at each of these solution pressures was measured in situ, and the $\mathrm{R}_{\mathrm{h}}$ distributions are given in Figure $\mathrm{S} 6$. The two data sets are consistent and suggest that the micelles at these two solvent pressures are physically similar, if not identical.



Figure S6. Comparison of the $\mathrm{R}_{\mathrm{h}}$ distributions determined using CONTIN for a solution of LF(5-4) micelles in $\mathrm{CO}_{2}$ at 350 and 400 bar.

A pitfall of quenching micelles from solution and characterizing them post-mortem is the possibility of forming and observing artifacts of the process. Indeed, micrographs of the LF5-4 frozen micelles revealed the formation of large, compound micelles in addition to the formation of vesicles. Figure S7 is a sample micrograph of the anomalous structures observed. 



Figure S7. TEM images of large compound micelles formed on quenching LF5-4 micelles from $\mathrm{CO}_{2}$. 